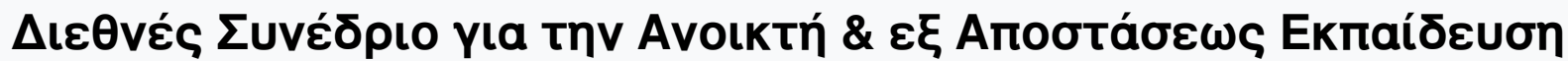

Tón. 6, Ap. 1A (2011)

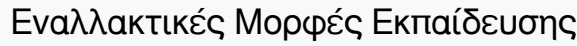

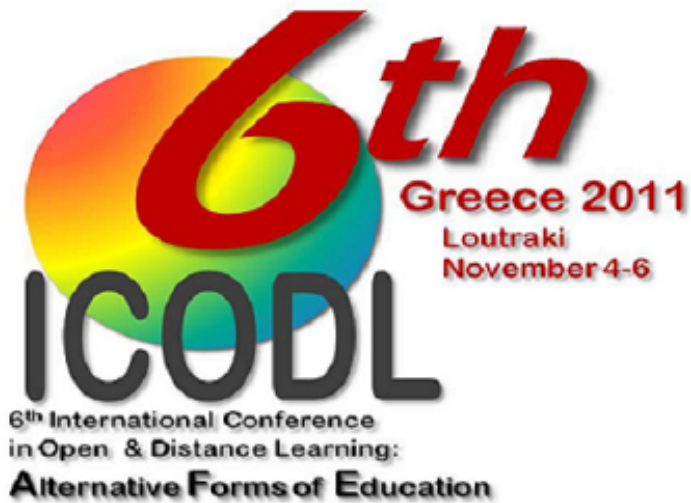

TOMOEA

PART/MEPOEA

in Open \& Distance Learning:

Alternative Forms of Education
A Proposal for the Development of a Flexible Delivery Policy for the Department of Marketing of the Technological Education Institution (TEI) of Athens

Dimitris Zondiros, Dimitris Novas, Maria Briana doi: $\underline{10.12681 / \text { icodl. }} .700$ 


\title{
A Proposal for the Development of a Flexible Delivery Policy for the Department of Marketing of the Technological Education Institution (TEI) of Athens
}

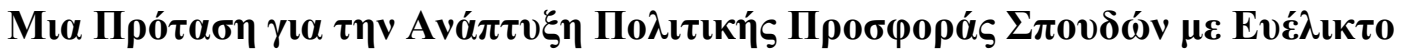 Трó

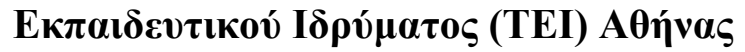

\author{
Dimitris Zondiros \\ Lecturer, Technological \\ Education Institution (T.E.I.) of \\ Athens, zondiros@otenet.gr
}

\author{
Dimitris Novas \\ Lecturer, Technological \\ Education Institution (T.E.I.) of \\ Athens,dnovas@teiath.gr
}

\author{
Maria Briana \\ Lecturer (on-contract), \\ Technological Education \\ Institution (T.E.I.) of Athens, \\ maria_briana@yahoo.com
}

\begin{abstract}
The undergraduate programme in Marketing offered by the Department of Marketing of the Technological Education Institution (TEI) of Athens is currently delivered using mainly the lecture-based approach for students 18-24 years of age. However, a number of factors, both internal and external, exert pressure towards redesigning delivery around a more flexible approach, which may target to both current students and future older applicants. These factors include, among others, a great demand for management studies, rigidity of organisational structures and a lack of focus on Life Long Learning to serve the needs of the changing student population. Therefore, Flexible Delivery is an approach well suited to address current and future students' needs in or above the 18-24 age range. So, the current organisational situation and the key elements for consideration are described and analysed (improvement in access and equity, flexibility of teacher - learner interactions, the appropriate tutor support, improvement of organisational processes and the nature and the scope of the administrative systems). These are followed by respective policy recommendations for this organization so as to respond to the new requirements deriving from the introduction of Flexible Delivery. These policy recommendations take into account the difficulties that are normally expected to arise and propose ways to overcome them. In any case, a gradual adaptation is preferable since that there are - and there will be - many challenges to be faced by the organisation.
\end{abstract}

\section{Пєрí $\eta \psi \eta$}

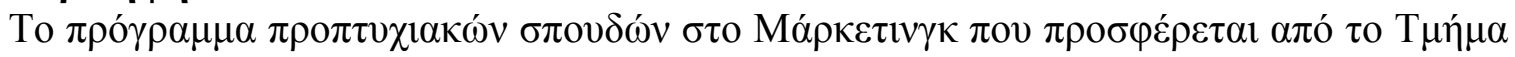

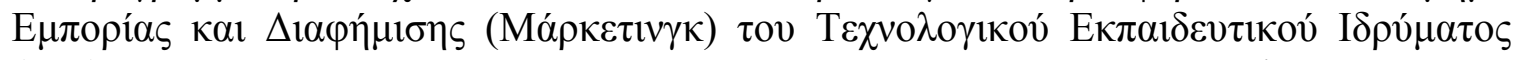

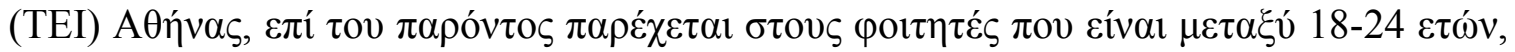

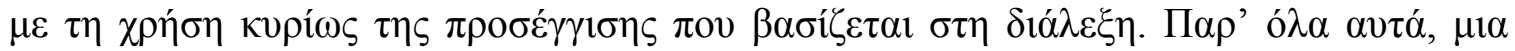

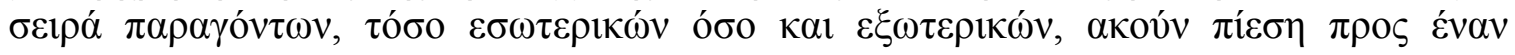

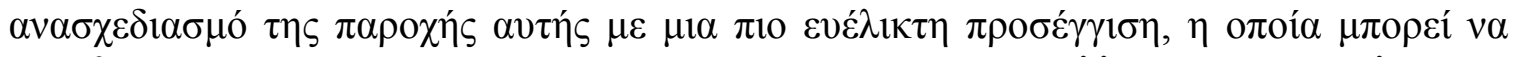

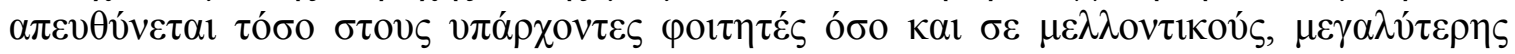

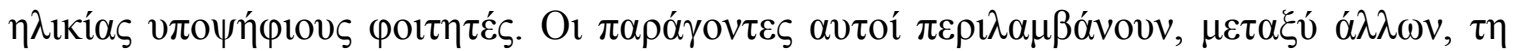

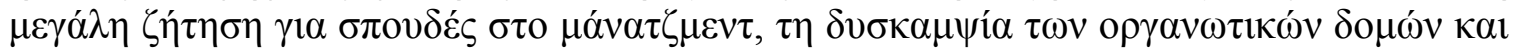




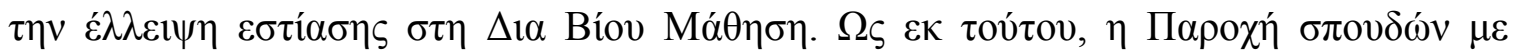

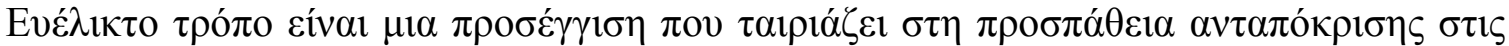

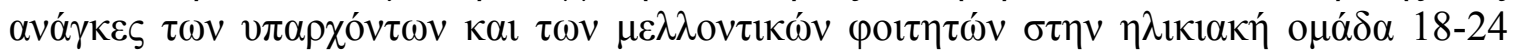

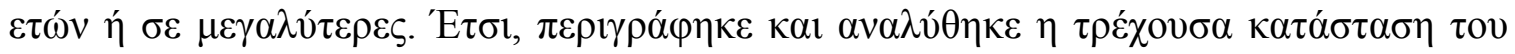

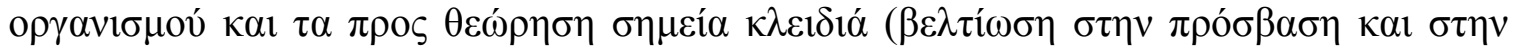

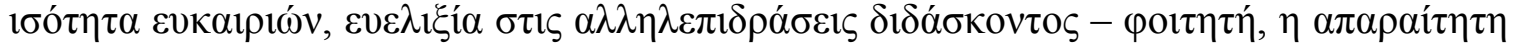

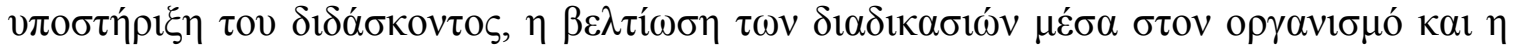

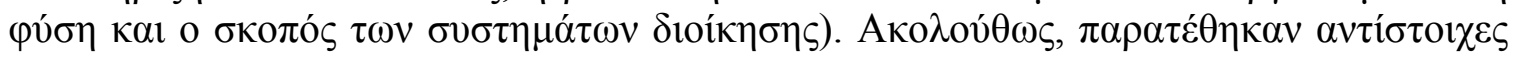

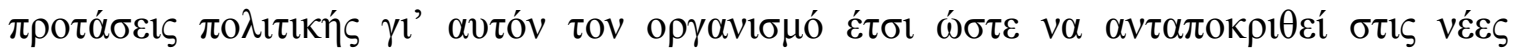

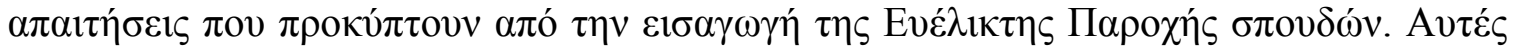

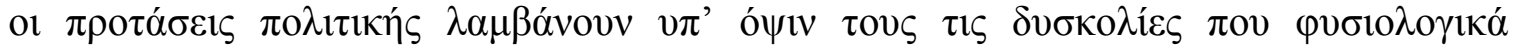

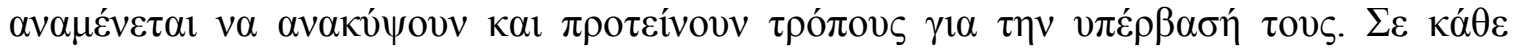

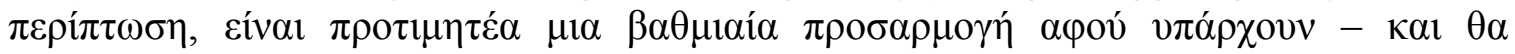

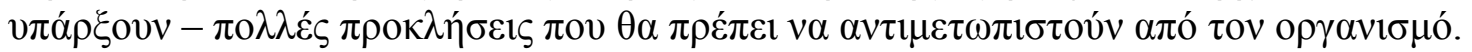

Key words: Flexible delivery, Flexible teaching and learning, Life long learning.

\section{Introduction}

The Department of Marketing of the Technological Education Institution (TEI) of Athens, Hellas offers an undergraduate programme of studies in Marketing using the lecture-based approach only. The students of this Department are currently in the $18-24$ age-range but older students are expected to be enrolled in the future following the establishment of the Institutes for Lifelong Education. The challenge of Flexible Delivery for the Department of Marketing is to create self-directed and motivated learners by providing them with more choices about where, when, what and how they learn supported by appropriately qualified staff through the creative and efficient use of new Information and Communication Technologies.

\section{The Context}

The organisational context consists of several external and internal variables that are interrelated and influence the Flexible Delivery policy proposal and formulation within the organisation. A brief description of them follows:

Educational

- Lack of clarity of the "new" concepts of Flexible Delivery, flexible learning, open learning etc. which leads to confusion about them. These "new" forms of learning may not be easily accepted and valued by both learners and their environment.

- Pressure exerted by other foreign institutions due to differences in teaching methods, assessment mechanisms and criteria.

- The need to accept that learners' needs must become the centre of the educational process and revise the current teaching and learning practice.

\section{Economic and technological}

- The Department receives much less funding while student numbers have been increased. Alternative sources of funding are very difficult to be sought. European Union (EU) funding is a possibility but we must bear in mind that it is of limited scope. 
- Inadequate resources, infrastructure and lack of modern Information and Communication Technologies (ICTs).

- Inadequate student and teacher support due to intrinsic barriers.

- Learners' knowledge, willingness and ability to use ICTs in a uniform way and the extent of their access to appropriate facilities are not known.

Social

- The demand for higher education continues to be great.

- There is a need for Life Long Learning due to changing student population that is seen more and more clearly.

- Stakeholders may have totally different views and priorities concerning the constituents of Flexible Delivery and reaching a consensus may be extremely difficult.

\section{Political}

- Inflexibility on where, when, what and how learners are able to learn due to existing legislation and centralisation of the educational and administrative structures.

- Flexible Delivery is not a top priority.

- Pressure for accountability, evaluation and quality assurance of higher education.

- Existing funding formulas and policies are based in the numbers of students admitted.

Industrial

- Labour market-orientation is a potential major thrust for future Flexible Delivery initiatives.

- Industry favours Flexible Delivery initiatives.

\section{Internal}

- Rigidity of organisational structures and of the way education is delivered.

- Closer contact with the labour market and the affiliations developed between alumni and the Department is an advantage for Flexible Delivery.

- The Department enjoys a good reputation and high-school graduates show a strong preference for it.

- Teaching and administrative staff is accustomed to traditional roles and resist to change.

Taking all the above into consideration, we can use the definition of Flexible Delivery given by Bell and Lefoe (1998, p. 72): "Flexible Delivery is an approach to teaching and learning which increases access to education for a wide range of students by offering greater student control over time, place and pace of study. Technology, where appropriate, is utilised to support communication and access to information, to move towards a more student centred approach to teaching and learning. The most appropriate delivery medium, (e.g. a lecture, a video or a book), can be chosen to meet the needs of students, and interaction can be facilitated through face-to-face contact or through supporting technology such as videoconference, phone, fax". 


\section{Key elements for consideration}

The organisation in question (the Department of Marketing) should provide higher education in Marketing through Flexible Delivery to existing (young) students and to older ones. Flexible Delivery seems to be more important for the second category as they are mature adults that will bring their own life and job experience with them, have different needs and learn in a different way. For the first category, the usefulness of Flexible Delivery lies mainly to its ability to provide them with study alternatives and help them to become self-directed lifelong learners. The Department needs to consider some dimensions of Flexible Delivery within and outside it and it has to find means to accomplish these goals.

To achieve this, some key elements have to be identified for consideration if policy is to address our organisation's Flexible Delivery needs.

The first one refers to the improvement in access and equity provided by the Department. These issues can be seen under the light of more flexibility in terms of customising the course content and teaching strategies and of credit transfer and recognition of formal prior learning and the elaboration of bridging programmes. The customisation of course content and teaching strategies are crucial since the Department will be able to be better adjusted to the needs of learners. This does not happen today as material has remained is written in the "old, good way" accompanied by the lecture-based approach. Credit transfer and recognition of formal prior learning will be another initiative to value learners' existing knowledge and experience. In addition, bridging programmes may be used so as to shorten the period of study of learners that have previous relevant education credentials.

The second one concerns the flexibility of teacher - learner interactions. This flexibility has to be enhanced by new modes of delivery (by "new modes" we mean modes that are new in the Hellenic higher education system - they may be "old" in other higher education systems). The use of new modes will foster flexibility in terms of place, time, and pace of learning. Moreover, the recognition of the changing nature of learner teacher interactions has to be made. The need for staff development is imperative and a special focus must be made on the changing role of the teacher in Flexible Delivery (Mandell and Herman, 1996).

The appropriate tutor support constitutes the third key element. As support is one of the most important constituents of Flexible Delivery initiative, one to one and group-based tutor support are considered valuable for the learners. In contrast with the massive, impersonal teaching, one to one and small group-based tutor support are the means by which the diversity of the learners is possible to be addressed. This tutor support has to be enriched with residential tutorials and seminars that provide the opportunity of closer contact and communication of all interested parties. The above can be accompanied by personal help and counselling to enable learners to overcome barriers and difficulties in their learning efforts.

The fourth key element refers to the improvement of organisational processes. This improvement may take the form of the collaboration with external institutions and bodies. Furthermore, the improvement of leadership and "management of change" skills is a priority for both Department's and TEI's top management. This goes "hand-in-hand" with the change of the organisation's culture. This change is, of course, something very demanding which takes time and needs a lot of work to be done. 
The nature and the scope of the administrative systems constitute the fifth key element. Flexible Delivery administrative systems have to become customer driven and easily understood. Administrative staff development is the most important issue here. An effort in re-engineering the whole administrative process would also be of great help, as it will enable the Department to amend and improve the existing procedures.

The sixth key element refers to the appropriate learning resources and technologies needed. To meet the needs for Flexible Delivery mentioned above, learning resources and technologies have to be selected accordingly. The mix of media to be used will be dictated by:

- The extent to which learners can access and use the medium (practicality, cost, personal preference)

- Instructors expertise in using it for course design and delivery

- The financial capacity and administrative infrastructures of the provider and

- The local and national communications infrastructure supporting the medium.

\section{The current organisational situation and the key elements for consideration}

The key elements described above must be viewed in the light of the Department's organisational situation. Of course, there will be significant facilitating and restraining forces (organisational strengths, weaknesses and deficiencies). For the first key element (improvement in access and equity), the customising of the course content and teaching strategies may face the lack of understanding of what Flexible Delivery is and the potential of "knowledge media" (Postle and Ellerton, 1999). New teaching strategies may not be welcome by the teaching staff, as they probably do not know what these strategies are. On the other hand, society and industry may support this change, as there is a growing need for Life Long Learning and changing student population. Credit transfer and recognition of prior learning will face many obstacles particularly on the part of some stakeholders (senior academic staff, political parties) that do not like higher education to be mingled with other levels of learning. Other stakeholders favour this initiative (industry, older students willing to enter or re-enter higher education). The bridging programmes will face the same problems also plus the justified concern of lack of knowhow on to design them.

The second key element (flexibility of teacher - learner interactions) and its associated new modes of delivery may face the barriers of resistance to change and faculty culture (Berge, 1998). Industry, again, and the pressure for more places in higher education along with the changing and expanding student body counterbalance the barriers mentioned before. The recognition of the changing nature of learner - teacher interactions will be something very difficult to be brought about as it contrary to faculty beliefs and culture. They do not want to abolish their perceived "superior role" by putting learners' needs first and above theirs. On the other hand, there is a need to accept that learners' needs must become the centre of the educational process.

The appropriate tutor support element may be more acceptable as there is already some experience in teaching small groups (in tutorial sessions and laboratory classes). But the one-to-one tutor support is rare and done informally an infrequently also. In addition, faculty or other staff members do not know why they must provide support and how this support has to be provided. One-to-one and small group-based tutor support, personal help and counselling "undermines" the perceived economic efficiency of the massive 
education system and is to be seen as a factor of additional cost. In this case, it is sure that their importance (Benza et al, 1999) is not understood or is underestimated. This may threaten the viability of the whole Flexible Delivery system (Gellman-Danley and Fetzner, 1998).

The fourth key element (improvement of organisational processes) is probably the most crucial one and the most difficult to cope with. There are many forces that exert pressure for the existence of leaders with true and visionary leadership abilities and experts in the management of change - the "open management" approach as described by Paul (1990). The same happens with the need for changing the organisation's culture. These forces are the collaborations with other institutions, the need for accountability and quality assurance and the need to do more with less. Resistance to change, lack of new leaders and drivers of change and delays to find and appoint them are restraining forces for organisational change to take place.

The change in nature and the scope of the administrative systems (the fifth key element) may have problems due to the rigidity of organisational and administrative structures (Postle and Ellerton, 1999) and the existing legislation and centralisation of these structures. Moreover, Flexible Delivery is not a top priority. The customer driven approach will face the same problems with the change and customisation of teaching strategies mentioned previously. The simplification of these structures may face respective problems also. The positive side is that the efficiency of the current structures has been put in question due to their failure to overcome certain problems (e.g. increased student numbers) and the opportunity to change them to the desired direction seems feasible.

The sixth key element which refers to the appropriate learning resources and technologies needed to support Flexible Delivery is probably the most problematic. The Department suffers from inadequate resources, infrastructure and lack of modern ICTs. It receives much less funding not in proportion with student numbers. The addition of new, older students may lead to deterioration. There is also inadequate student and teacher support due to intrinsic barriers. Furthermore, young and older learners' knowledge, willingness and ability to use ICTs in a uniform way and the extent of their access to appropriate facilities are not known. On the other side, there is possibility for EU funding but we must bear in mind that it is of limited scope. EU supports infrastructure creation and modernisation and this can be exploited to a large extent.

\section{Key policy recommendations}

Small, gradual steps have to be made in the beginning so as to avoid serious mistakes and allow for adjustments and changes where and when needed. However, it is not possible to cover all aspects of Flexible Delivery in the given context. Some organisation-specific key policy recommendations will be identified in relation to the key elements described above.

\section{Policy recommendation 1}

The Department cannot undertake the duty for customising the course content and teaching strategies. A reasonable alternative is the introduction of the distance education / learning mode as a first effort. Material already developed by the Hellenic Open University (HOU) is available. This material was created with the mature / adult learner 
in mind and its adoption will save the Department a lot of money. This material covers the majority of the Department's curriculum. This way, an additional mode of study can be offered at very low cost. The HOU is expected to minimise or eliminate royalties for its material due to the protocol for mutual co-operation with the rest of the ('traditional') Hellenic Higher Education Institutions (HEIs). To avoid obstacles and oppositions with informal prior learning assessment, we can develop a process for credit transfer and recognition of prior formal learning. For example, formal prior learning is the case of the graduates of the Institutes of Vocational Training. The two-year study in these Institutes leads to a professional certificate acquired after success in the Professional Certification Examinations. The specialisations they offer are similar to the Departments' ones (trade and promotion, advertising and sales). By awarding them certain amounts of credits, a bridging or degree-completion programme can be designed and executed. Moreover, the expected operation of the Hellenic Qualifications Framework is expected to facilitate the recognition of formal, informal and non-formal learning also (Fotopoulos and Goulas, 2010).

\section{Policy recommendation 2}

The recognition of the changing nature of learner - teacher interactions can only be achieved through staff development. Staff development must be seen as an instrument for organisational change (Robinson, 1998). New teaching strategies and methods (Sparkes, 1993), awareness of how learners have changed, the new roles of the teacher, new assessment methods etc. are the topics in which they must receive training. A good option for them would be to attend the postgraduate modules "Adult Education Methodology", "Design, Management and Evaluation of Adult Education Programmes", "Contemporary Approaches to Adult Education" and "Open and Distance Education" developed and delivered by the HOU. Again, cost can be compensated through the mutual co-operation agreement. These modules will provide staff the necessary knowledge and first-hand experience of studying at a distance. Material and non-material incentives must be given them to do so.

\section{Policy recommendation 3}

The appropriate tutor support needs a separate management sub-system (Freeman, 1997). Staff development is responsible for making tutors: a) gateways to other resources; b) providers of feedback; c) helpers with personal problems and d) assessors. The postgraduate modules mentioned above can serve this aim except (c) in which the help of the TEI's social and counselling service can be used to provide the training needed.

\section{Policy recommendation 4}

The answers to the question "why go flexible?" are the reasons for bringing change about and get leadership informed of what is expected by it. These answers are (Race, 1996):

- The pressure is on us due to the increasing competition

- We need to work together (with other providers of education and training)

- The (traditional) systems are changing.

- Funding is diminishing.

- Our learners are more different.

- Students' expectations are more varied. 
- Many students feel over stretched - we have to ease their burden.

- Quality control and accountability are more important.

- The world outside is using more flexible learning.

- Learning to learn is more important as an outcome of higher education.

These issues dictate the change of attitudes and ways of thinking and dealing with everyday activities. If current management (both at TEI and Departmental level) cannot be adjusted to the new requirements, they must be replaced. This sounds stranger but the success comes only when top management understands and supports the new initiatives.

\section{Policy recommendation 5}

The customer driven approach as well as the flexibility needed for change in nature and the scope of the administrative systems can only be achieved through administrative staff development actions. The rationale is the same as in the case of teaching staff development activities. On the other hand, the issue of simplicity and understanding of these systems must be achieved through the means of re-engineering. An outside organisation (e.g. a consultancy firm) may undertake this task. Due to limited funding, the alternative of assigning this task to a university Department must be examined.

\section{Policy recommendation 6}

The issue of the appropriate learning resources and technologies needed to support Flexible Delivery has direct relationship with inadequate resources, infrastructure and lack of modern ICTs; inadequate student and teacher technical support; learners' knowledge, willingness and ability to use ICTs in a uniform way and the extent of their access to appropriate facilities. All these suggest the use of low-cost second-generation media (Taylor's "multi-media model" as cited in Postle and Ellerton, 1999). These media (print, audiotape, videotape) are the ones also used by the HOU as students feel comfortable with, have access and experience to use them (Cuskelly, et al, 1997). For the near future, Taylor's fourth-generation alternative (the Flexible Learning model Interactive Multimedia, Internet-based access to WWW resources and Computer Mediated Communications [CMC]) has to be considered because of its advantages (Mason, 1994). This will be the case provided that the necessary funding has been secured, the limits of technology have been well defined (Bates, 1994) and both Department and learners are willing and capable of using the new ICTs and exploiting their full potential.

\section{Conclusion}

The introduction of Flexible Delivery in the organisation of the Department of Marketing of the TEI of Athens is a difficult and time-consuming task. In this paper, an attempt was made to make a proposal for the development of a Flexible Delivery policy for this Department taking into account its characteristics and particularities as well as the forces that shape its external environment. Six key elements expected to be of paramount importance were identified and the associated strengths, weaknesses and deficiencies related to them were also described. Respective policy recommendations made on the basis of this description so as to address the needs deriving form the introduction of Flexible Delivery within this organisation. The implementation of the policy proposed must be gradual and must allow for time in order the Department and its constituent parts 
adjust in the new situation and be able to respond more effectively and efficiently to the challenges Flexible Delivery is to pose in the future.

\section{References}

Bates, A.W. (1994). Educational Aspects of the Telecommunications Revolution, Proceedings ICDEDEANZ, Windows of the Future Conference, Wellington, New Zealand pp. 39, pp. 43-51

Bell, M. and Lefoe, G. (1998). Curriculum Design for Flexible Delivery - Massaging the Model, Australian Society for Computers in Learning in Tertiary Education Conference Proceedings, 1416 December, University of Wollongong, pp. 63-73

Benza, T.E.S., Chitsika, R. et al. (1999). A Critical Assessment of Learner Support Services Provided by the Zimbabwe Open University, Empowerment through Knowledge and Technology, Pan Commonwealth Forum on Open Learning Case Studies A-G, Brunei Darussalam, 1-5 March

Berge, Z. (1998). Barriers to Online Teaching in Post-Secondary Institutions: Can Policy Changes Fix It?, Online Journal of Distance Learning Administration, vol. 1, No 2, State University of West Georgia, Distance Education Center. Retrieved on 19 April, 2011 from http://www.westga.edu/ distance/Berge12.html.

Cuskelly, E., Danaher, P. \& Purnell, K. (1997). Just which Technology do Distance Students Really Want? Results of Focus Group Research, UCQ ODLLA paper

Fotopoulos, N and Goulas, Chr. (2010). The Certification and Recognition of Qualifications at the Epicentre of the European Education Policy in Karalis, Th. (ed.) Life Long Learning and Certification, Institute of Labour, Athens (in Hellenic [Greek])

Freeman, R. (1997). Managing Open Systems, Kogan Page, London

Gellman-Danley, B. and Fetzner, M. J. (1998). Asking the Really Tough Questions: Policy Issues for Distance Learning, Online Journal of Distance Learning Administration, vol. 1, No 2, State University of West Georgia, Distance Education Center. Retrieved on 20 April, 2011 from http://www.westga.edu/ distance/danley11.html

Hawkridge, D. (1997). H801 Foundations of Open and Distance Education, Block 1, Theory and Practice in Open and Distance Education, Milton Keynes, The Open University / Deakin University, University of South Australia

Mandell, A. and Herman, L. (1996). From Teachers to Mentors: Acknowledging Openings in the Faculty Role in Mills, R. and Tait, A. (eds), Supporting the Learner in Open and Distance Learning, Pitman, London

Mason, R. (1994). Implications for students, teachers and organisations, ch. 3 in Communications Media in Open and Flexible Learning, Kogan Page, London, pp. 37-49

Paul, R.H. (1990). Towards open management: A value-driven leadership Approach, ch. 5 in Open Learning and Open Management, Kogan Page, London, pp. 66-73

Postle, G. and Ellerton, N. (1999). A Changing Role for Teachers On-line: A Case Study in Higher Education in Australia, Empowerment through Knowledge and Technology, Pan Commonwealth Forum on Open Learning Case Studies A-G, Brunei Darussalam, 1-5 March

Race, Ph. (1996). Practical Pointers to Flexible Learning, material prepared for the Certificate in Teaching in Higher Education, University of Durham

Robinson, B. (1998). A Strategic Perspective on Staff Development for Open and Distance Learning, in Latchem, C. and Lockwood, F. (eds) Staff Development in Open and Flexible Learning, Routledge, London

Sparkes, J. (1993). Distance Education and Conceptual Learning in Parer, M. (ed.) Developing Open Courses, Centre for Distance Learning, Churchill, Victoria, Australia 